\title{
BRAIN TUMOUR PRESENTING AS A DISLOCATED SHOULDER
}

\author{
D. S. ELLIOTT
}

Posterior fracture-dislocation of the shoulder is uncommon, accounting for only $0.9 \%$ in a series of over 1500 shoulder injuries (Neer 1970). In that study, four of the eight cases of unilateral fracture-dislocation were caused by a seizure, and it is said that bilateral posterior fracturedislocation is virtually pathognomonic of a convulsive episode (Din and Meggitt 1983). There have been no previous reports of brain tumours presenting as posterior fracture-dislocation of the shoulder in the English language literature.

Case report. A 50-year-old man presented to casualty having woken with pain in the right shoulder. There was no history of trauma but he described an influenza-like illness, with heachaches for 10 days. There was no significant past history, he took no regular medication and drank alcohol only occasionally. On examination there were no abnormal findings apart from pain on moving the right shoulder. Radiographs demonstrated a two-part posterior fracture-dislocation and this was confirmed by a CT scan (Fig. 1). In view of the fact that this injury is usually caused by a seizure, a CT scan of his head was also performed (Fig. 2). This showed a large space-occupying lesion in the left frontal lobe. The neurosurgical team advised that his shoulder should be treated first and, under general anaesthesia with image intensification, closed reduction of the fracture-dislocation was achieved and found to be stable.

Subsequently, an excision-biopsy showed that the tumour was a benign macrocystic meningioma. A further scan confirmed complete excision; his prognosis is therefore excellent.

Recovery from his shoulder injury was extremely good and at three months he had full range of movements and normal function.

Discussion. Shaw (1971) proposed a mechanism for posterior fracture-dislocation of the shoulder during a seizure, and the CT scan in Figure 1 of the shoulder in this case confirms his suggestion: as the deforming forces continue, the posterior lip of the glenoid acts like a wedge and shears the head of the humerus along the anatomical

D. S. Elliott, FRCS, Orthopaedic Registrar

St. George's Hospital, Blackshaw Road, Tooting, London SW 17 0GT, England.

(C) 1990 British Editorial Society of Bone and Joint Surgery $0301-620 \mathrm{X} / 90 / 5 \mathrm{R} 82 \$ 2.00$

J Bone Joint Surg [Br] 1990; 72-B :925.

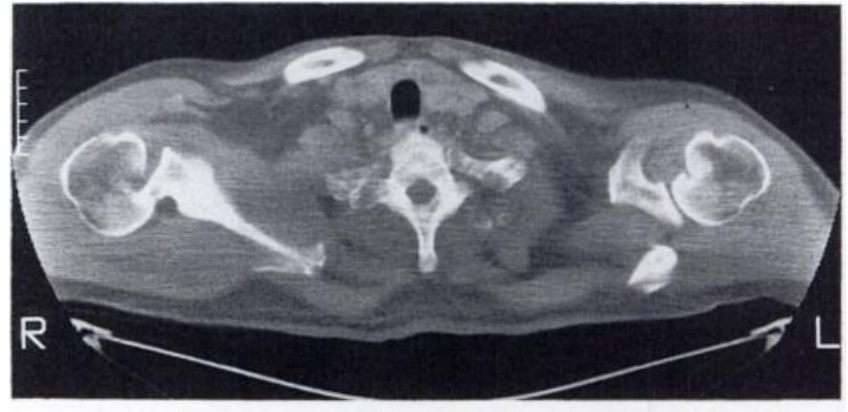

Fig. 1

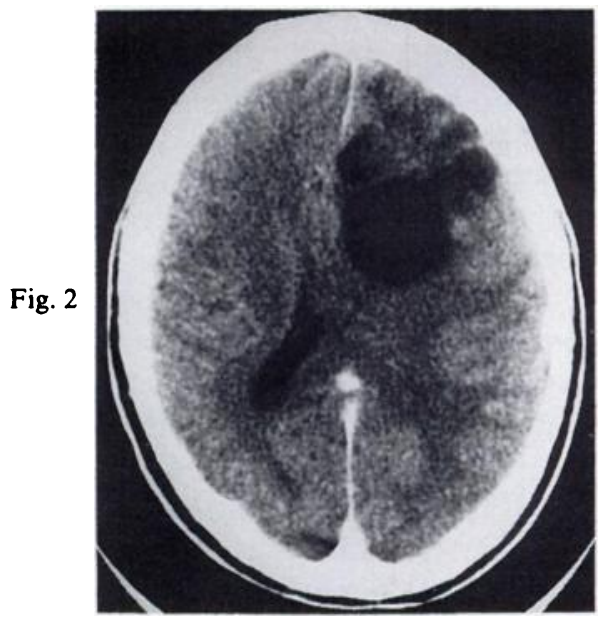

neck. Further massive contraction of the shoulder girdle muscles would have resulted in avulsion of the greater and lesser tuberosities and a four-part fracture.

This case illustrates the importance of recognising the association between posterior fracture dislocation of the shoulder and a convulsive episode. Full investigation, including CT scanning of the head, is recommended for patients presenting with this injury who have no history of trauma or previous seizures.

No benefits in any form have been received or will be received from a commercial party related directly or indirectly to the subject of this article.

\section{REFERENCES}

Din KM, Meggitt BF. Bilateral four-part fractures with posterior dislocation of the shoulder: a case report. J Bone Joint Surg [Br] $1983 ; 65-B: 176-8$.

Neer CS II. Displaced proximal humeral fractures. Part I. Classification and evaluation. J Bone Joint Surg [ Am] 1970; 52-A :1077-89.

Shaw JL. Bilateral posterior fracture-dislocation of the shoulder and other trauma caused by convulsive seizures. J Bone Joint Surg [Am] 1971; 53-A :1437-40. 